\title{
A Case of Relapsing Polychondritis Successfully Treated with Combination of a Glucocorticoid and Cyclosporine
}

\author{
Koichiro Takahashi, Hiroshi Inoue, Hironori Sadamatsu, Hitomi Umeguchi, \\ Naoko Sueoka-Aragane, Shinya Kimura* \\ Division of Hematology, Respiratory Medicine and Oncology, Department of Internal Medicine, Faculty of \\ Medicine, Saga University, Saga, Japan \\ Email: ${ }^{*}$ shkimu@cc.saga-u.ac.jp
}

Received 4 February 2015; accepted 28 June 2015; published 1 July 2015

Copyright @ 2015 by authors and Scientific Research Publishing Inc.

This work is licensed under the Creative Commons Attribution International License (CC BY). http://creativecommons.org/licenses/by/4.0/

(c) (i) Open Access

\begin{abstract}
Relapsing polychondritis is a rare cartilaginous inflammatory disease affecting the external ear, nose, peripheral joints and tracheobronchial tree. It is characterized by recurrent inflammation and degeneration of cartilage and connective tissue. A 72-year-old man complained of dyspnea, cough and wheezing for 2 months. Diffuse wall thickening and narrowing from the trachea to segmental bronchus were seen on chest CT. Tracheostomy was performed in order to avoid asphyxia, and he was diagnosed as relapsing polychondritis on the basis of pathology evaluation of a tracheal biopsy specimen. He was treated with high doses of a glucocorticoid, with which his symptoms improved. However, the cough and wheezing recurred after tapering of the glucocorticoid. His symptoms thereafter were improved by combination of the glucocorticoid with cyclosporine. The immunosuppressive agent provided effective treatment for glucocorticoid-resistant relapsing polychondritis.
\end{abstract}

\section{Keywords}

Relapsing Polychondritis, Trachea, Cyclosporine

\section{Introduction}

Relapsing polychondritis (RP) is a rare disorder with an estimated incidence of 3 per million populations [1] [2]. $\mathrm{RP}$ is reportedly related to autoimmunity, and involves the external ear, nose, peripheral joints and tracheobron-

\footnotetext{
${ }^{*}$ Corresponding author.
}

How to cite this paper: Takahashi, K., Inoue, H., Sadamatsu, H., Umeguchi, H., Sueoka-Aragane, N. and Kimura, S. (2015) A Case of Relapsing Polychondritis Successfully Treated with Combination of a Glucocorticoid and Cyclosporine. International Journal of Clinical Medicine, 6, 439-443. http://dx.doi.org/10.4236/ijcm.2015.67057 
chial tree [3]. In cases with involvement of the tracheobronchial cartilage, symptoms such as non-productive cough, wheezing and dyspnea occur, although fatal asphyxia has also been reported [4]. Diagnosis of RP is confounded by the similarity of the symptoms to those of bronchial asthma [5]. The histological picture is characterized by perichondral infiltration of lymphocytes, polymorphonuclear cells and macrophages in the initial stage, and disrupted cartilage structure and invading granulation in the stage of progression [6]. Treatment of RP includes high doses of glucocorticoids, although RP recurrence is sometimes observed while tapering the glucocorticoid. Immunosuppressive agents are also used in combination with glucocorticoids in patients with a poor response to the glucocorticoid [6]. However, standard regimens of immunosuppressive agents have not been established. Here, we report a case of airway-limiting RP that was successfully treated by combination of a glucocorticoid and cyclosporine.

\section{Case Report}

A 72-year-old man was admitted to Saga University Hospital because of dyspnea, cough and wheezing since 2 months. He had a 40 pack-year history of smoking. At the age of 60 years, he was diagnosed with bronchial asthma by a primary care physician. He had no family history of asthma or other diseases. He was prescribed daily inhalation corticosteroid therapy (fluticasone propionate $400 \mu \mathrm{g} /$ day). His blood pressure and pulse rate were 142/88 mmHg and $90 \mathrm{bpm}$, respectively, with a $\mathrm{SpO}_{2}$ of $95 \%$ while breathing $5 \mathrm{~L} / \mathrm{min}$ of oxygen via a mask. He had wheezing and inspiratory stridor in the region of the central chest, with no evidence of saddle nose or swelling of the ear auricles. White blood cell (WBC) count and C-reactive protein (CRP) were increased to $12,100 / \mu \mathrm{l}$ and $14.49 \mathrm{mg} / \mathrm{dl}$, respectively. Anti-type II collagen antibody in serum was positive (>145 EU/ml). In contrast, anti-nuclear antibody and anti-neutrophil cytoplasmic antibody were negative. Chest computed tomography (CT) scan demonstrated massive wall thickening and marked stenosis of the trachea and bronchi, up to the level of the segmental bronchi (Figure 1(a), Figure 1(b)).

Due to the risk of asphyxia due to airway stenosis, he underwent a tracheostomy, and a small piece of tracheal tissue was removed for biopsy. Pathology examination of the tracheal tissue showed inflammatory granulation with lymphocytes and neutrophil infiltration of the surrounding cartilage (Figure 2). He was diagnosed with RP

(a)

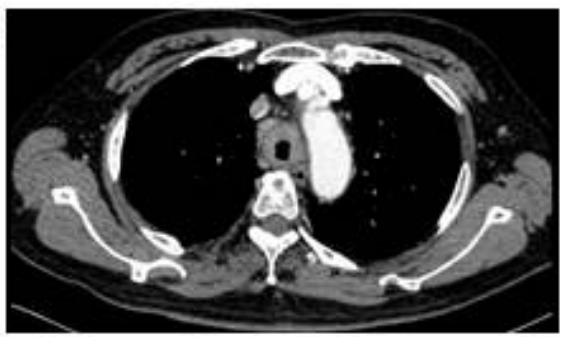

(c)

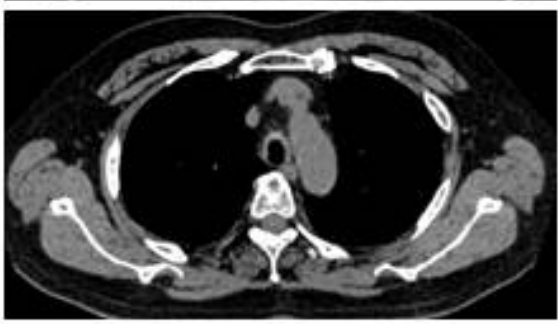

(e)

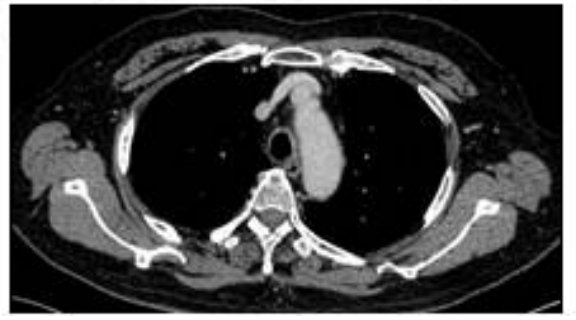

(b)

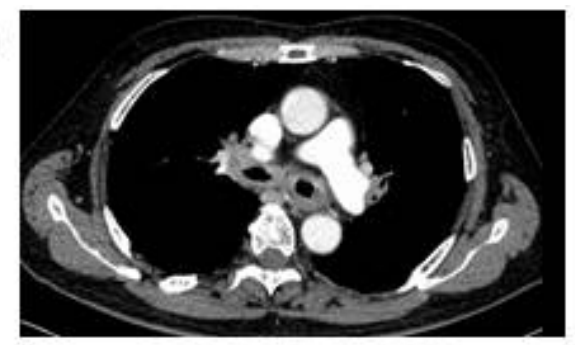

(d)

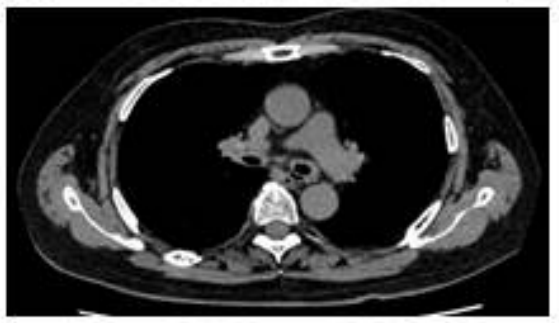

(f)

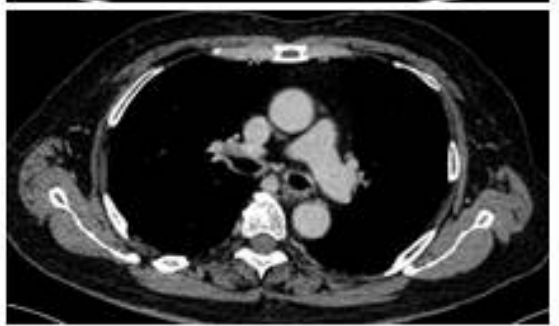

Figure 1. Chest computed tomography (CT) findings. Tracheal and bronchial findings at the time of diagnosis (a) (b); after 3 months treatment (c) (d) and after 6 months treatment (e) (f). 


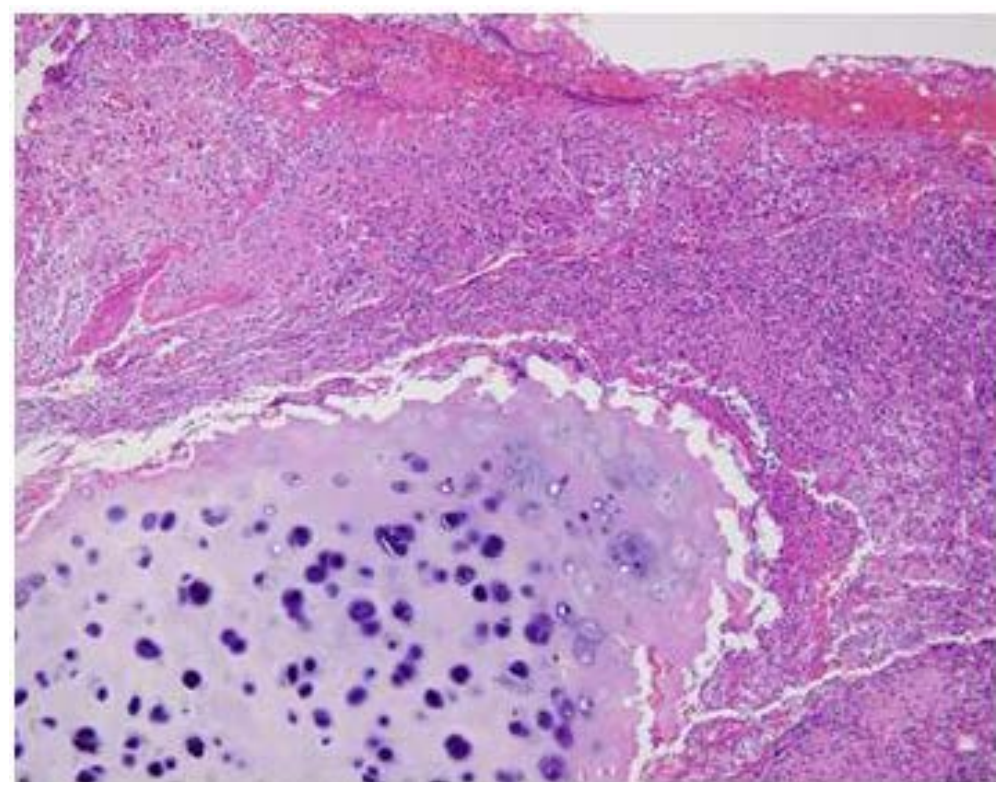

Figure 2. Pathology findings of the trachea observed using hematoxylin-eosin staining $(\times 80)$.

and was treated with high dose glucocorticoid (prednisolone $60 \mathrm{mg} / \mathrm{day}, 1.0 \mathrm{mg} / \mathrm{kg} / \mathrm{day}$ ). Initial treatment with the glucocorticoid was effective in relieving airway stenosis. Symptoms of dyspnea and wheezing improved after treatment for 1 month. Serum levels of CRP became undetectable. Wall thickening and stenosis of the trachea and bronchi, as seen by a chest CT scan, decreased after 3 months treatment (Figure 1(c), Figure (d)). However, at the time of tapering the prednisolone to $30 \mathrm{mg} /$ day, serum CRP increased again. Hence, he was treated with combination treatment of prednisolone and cyclosporine. The cyclosporine dose was adjusted to maintain the trough blood concentration between $100 \mathrm{ng} / \mathrm{ml}$ and $150 \mathrm{ng} / \mathrm{ml}$. Prednisolone was gradually reduced to $10 \mathrm{mg}$ /day, while cyclosporine was continued at the same dose. A CT scan repeated at 6 months after initiating treatment showed a further decrease in stenosis of the trachea and bronchi (Figure 1(e), Figure 1(f)). To date, 12 months after treatment initiation, the patient remains stable, with continued combination treatment with $10 \mathrm{mg} /$ day prednisolone and $100 \mathrm{mg}$ cyclosporine.

\section{Discussion}

Relapsing polychondritis (RP) is an autoimmune disorder in which cartilaginous tissues are the targets of inflammation [1]. The pathogenesis of RP remains unknown. However, immune abnormalities are often observed several years before RP developed, suggesting that it is a type of autoimmune disease. Frances et al. reported that 51 of 200 patients (25.5\%) have other associated autoimmune diseases, such as systemic lupus erythematosus, autoimmune thyroid disease and mixed connective tissue disease, and myelodysplastic syndrome co-existed with RP in 22 of 200 patients (11\%) [7].

RP is characterized by inflammation of cartilage, hence serum CRP levels and erythrocyte sedimentation rate (ESR) are increased in correlation with disease activity [6]. Another report on patients with RP found that 50\% were positive for serum anti-type II collagen antibody [8]. Airway manifestations are present in about $50 \%$ of patients with RP. They are the most serious organ involvement and predict a poor prognosis [9]. A CT scan is useful for evaluation of the tracheobronchial wall for diagnosis of RP [2]. Bone scintigraphy and positron emission tomography (PET) are also helpful in the diagnosis of RP [10].

The vast majority of patients with RP are treated with glucocorticoids. The recommended initial dose of glucocorticoids is $1.0 \mathrm{mg} / \mathrm{kg} /$ day of prednisolone for patients with sensorineural hearing loss, vestibular symptoms, ocular involvement, vascular complications and respiratory involvement [6]. Relapses of RP have a tendency to occur when glucocorticoids are tapered too rapidly. Even if glucocorticoids are gradually reduced, RP activity does increase in some cases. Several immunosuppressive agents have been used to reduce the long term use of 
glucocorticoids. Methotrexate and azathioprine have been successfully used in refractory cases of RP [11] [12]. Cyclosporine has helped in several cases that were refractory to other agents [13]. Cyclophosphamide by oral or intravenous administration is also used in refractory cases [14]. Recently, specific molecular targeted antibodies, such as infliximab (TNF $\alpha$ ) and tocilizumab (IL-6 receptor) have been successfully used in the treatment of RP [15] [16].

In the present case, treatment with the combination of glucocorticoid and cyclosporine was effective. The patient has maintained a remission state by these combination treatments. Cyclosporine reportedly inhibits the function of helper $\mathrm{T}$ cells and production of pro-inflammatory cytokines [17]. Better effects against RP with combination treatment suggest that glucocorticoids and cyclosporine might have additive effects. Future studies involving a larger case series are needed to establish more effective treatment for RP.

\section{Summary}

Combination treatment with a glucocorticoid and cyclosporine was effective for the treatment of glucocorticoidresistant relapsing polychondritis.

\section{Acknowledgements}

The authors thank Dr. Kazutoshi Komiya for preparation of the manuscript.

\section{Conflict of Interests}

All authors declare that they have no conflicts of interest related to this report. The written informed consent was obtained from patient for publication of this report.

\section{References}

[1] McAdam, L.P., O’Hanlan, M.A., Bluestone, R. and Pearson, C.M. (1976) Relapsing Polychondritis: Prospective Study of 23 Patients and a Review of the Literature. Medicine (Baltimore), 55, 193-215. http://dx.doi.org/10.1097/00005792-197605000-00001

[2] Kent, P.D., Michet Jr, C.J. and Lutha, H.S. (2004) Relapsing Polychondritis. Current Opinion in Rheumatology, 16, 56-61. http://dx.doi.org/10.1097/00002281-200401000-00011

[3] Letko, E., Zafirakis, P., Baltatzis, S., Voudouri, A., Livir-Rallatos, C., et al. (2002) Relapsing Polychondritis: A Clinical Review. Seminars in Arthritis and Rheumatism, 31, 384-395. http://dx.doi.org/10.1053/sarh.2002.32586

[4] Ernst, A., Rafeq, S., Boiselle, P., Sung, A., Reddy, C., et al. (2009) Relapsing Polychondritis and Airway Involvement. Chest, 135, 1024-1030. http://dx.doi.org/10.1378/chest.08-1180

[5] Sarodia, B.D., Dasgupta, A. and Mehta, A.C. (1999) Management of Airway Manifestations of Relapsing Polychondritis: Case Reports and Review of Literature. Chest, 116, 1669-1675. http://dx.doi.org/10.1378/chest.116.6.1669

[6] Lahmer, T., Treiber, M., von Werder, A., Foerger, F., Knopf, A., et al. (2010) Relapsing Polychondritis: An Autoimmune Disease with Many Faces. Autoimmunity Reviews, 9, 540-546. http://dx.doi.org/10.1016/j.autrev.2010.02.016

[7] Frances, C., El Rassi, R., Laporte, J.L., Rybojad, M., Papo, T., et al. (2001) Dermatologic Manifestations of Relapsing Polychondritis. A Study of 200 Cases at a Single Center. Medicine (i), 80, 173-179. http://dx.doi.org/10.1097/00005792-200105000-00003

[8] Terato, K., Shimomizu, Y., Katayama, K., Takemitsu, Y., Yamashita, I., et al. (1990) Specificity of Antibodies to Type II Collagen in Rheumatoid Arthritis. Arthritis Rheumatology, 33, 1493-1500. http://dx.doi.org/10.1002/art.1780331006

[9] Eng, J. and Sabanathan, S. (1991) Airway Complications in Relapsing Polychondritis. Annals of Thoracic Surgery, 51, 686-692. http://dx.doi.org/10.1016/0003-4975(91)90348-T

[10] Yamashita, H., Takahashi, H., Kubota, K., Ueda, Y., Ozaki, T., et al. (2014) Utility of Fluorodeoxyglucose Positron Emission Tomography/Computed Tomography for Early Diagnosis and Evaluation of Disease Activity of Relapsing Polychondritis: A Case Series and Literature Review. Rheumatology (Oxford), 53, 1482-1490.

http://dx.doi.org/10.1093/rheumatology/keu147

[11] . Trentham, D.E. and Le, C.H. (1998) Relapsing Polychondritis. Annals of Internal Medicine, 129, 114-122. http://dx.doi.org/10.7326/0003-4819-129-2-199807150-00011

[12] Park, J., Gowin, K.M. and Schumacher Jr., H.R. (1996) Steroid Sparing Effect of Methotrexate in Relapsing Polychondritis. The Journal of Rheumatology, 23, 937-938. 
[13] Priori, R., Paroli, M.P., Luan, F.L., Abdulaziz, M., Pivetti Pezzi, P. and Valesini, G. (1993) Cyclosporin A in the Treatment of Relapsing Polychondritis with Severe Recurrent Eye Involvement. British Journal of Rheumatology, 32, 352. http://dx.doi.org/10.1093/rheumatology/32.4.352

[14] Stewart, K.A. and Mazanec, D.J. (1992) Pulse Intravenous Cyclophosphamide for Kidney Disease in Relapsing Polychondritis. The Journal of Rheumatology, 19, 498-500.

[15] Marie, I., Lahaxe, L., Josse, S. and Levesque, H. (2009) Sustained Response to Infliximab in a Patient with Relapsing Polychondritis with Aortic Involvement. Rheumatology, 48, 1328-1329. http://dx.doi.org/10.1093/rheumatology/kep224

[16] Wallace, Z.S. and Stone, J.H. (2013) Refractory Relapsing Polychondritis Treated with Serial Success with Interleukin 6 Receptor Blockade. The Journal of Rheumatology, 40, 100-101. http://dx.doi.org/10.3899/jrheum.120381

[17] Takeda, K., Nagasaka, K. and Miyasaka, N. (2005) Polymyositis/Dermatomyositis and Interstitial Lung Disease: A New Therapeutic Approach with T-Cell-Specific Immunosuppressants. Autoimmunity, 38, 383-392. http://dx.doi.org/10.1080/08916930500124023 